\title{
Postnatal Cerebral Hyperoxia Is Associated with an Increased Risk of Severe Retinopathy of Prematurity
}

\author{
Anne E. Richter ${ }^{\mathrm{a}} \quad$ Arend F. Bos $^{\mathrm{a}} \quad$ E. Angela Huiskamp ${ }^{\mathrm{b}}$ Elisabeth M.W. Kooi ${ }^{\mathrm{a}}$ \\ ${ }^{a}$ Division of Neonatology, University of Groningen, University Medical Center Groningen, Beatrix Children's \\ Hospital, Groningen, The Netherlands; ${ }^{b}$ Department of Ophthalmology, University of Groningen, University Medical \\ Center Groningen, Groningen, The Netherlands
}

\section{Keywords}

Retinopathy of prematurity - Cerebral oxygen saturation .

Arterial oxygen saturation · Hyperoxia · Near-infrared

spectroscopy

\section{Abstract}

Background: High arterial oxygen saturation $\left(\mathrm{SaO}_{2}\right)$ is associated with the development of retinopathy of prematurity (ROP), but difficult to avoid. Objective: To assess the association between severe ROP and a burden of cerebral and arterial hyperoxia. Methods: We retrospectively analyzed 225 preterm infants born $\leq 30$ weeks' gestation. The cerebral oxygen saturation $\left(\mathrm{r}_{\mathrm{c}} \mathrm{SO}_{2}\right)$ and $\mathrm{SaO}_{2}$ were measured within the first $96 \mathrm{~h}$ after birth. We determined the burden of both cerebral and arterial hyperoxia, which was defined as the percentage of time spent at saturation thresholds exceeding 85 and $90 \%$, respectively. Their association with severe ROP (prethreshold disease type 1) was tested using logistic regression analyses. Results: Median gestational age (GA) was 28.0 weeks (interquartile range 26.7-29.0) and mean birth weight $1,032 \mathrm{~g}( \pm 281 \mathrm{SD})$. Eight infants developed severe ROP. Infants with severe ROP spent more time at cerebral hyperoxic levels than infants without severe ROP (medians 30 vs. $16 \%$ ). Adjusted for GA, for every $10 \%$ increase in burden of cerebral hyperoxia, the OR for developing ROP was 1.50 $(95 \% \mathrm{Cl} 1.09-2.06, p=0.013)$. A burden of arterial hyperoxia was not associated with ROP. Infants with severe ROP experienced even less arterial hyperoxia, although not statistically significant. Conclusions: Cerebral hyperoxia may be a better early predictor of severe ROP than arterial hyperoxia. Moreover, under strict oxygen management, cerebral hyperoxia in these infants may result from cerebral immaturity rather than a high $\mathrm{SaO}_{2}$. Whether reducing cerebral hyperoxia is feasible and might prevent ROP needs to be further examined.

(c) 2019 The Author(s) Published by S. Karger AG, Basel

\section{Introduction}

With improved survival of preterm infants, retinopathy of prematurity (ROP) has become an important cause of childhood blindness [1]. Hyperoxia plays an initiating role in the pathogenesis of ROP. While the fetal arterial oxygen saturation $\left(\mathrm{SaO}_{2}\right)$ is physiologically low, preterm birth suddenly exposes an incompletely vascularized retina to hy- 
Fig. 1. Inclusion flowchart. GA, gestational age; NIRS, near-infrared spectroscopy; ROP, retinopathy of prematurity.
Infants eligible for inclusion at GA $\leq 30$ weeks

January 2012-2017

$(n=326)$

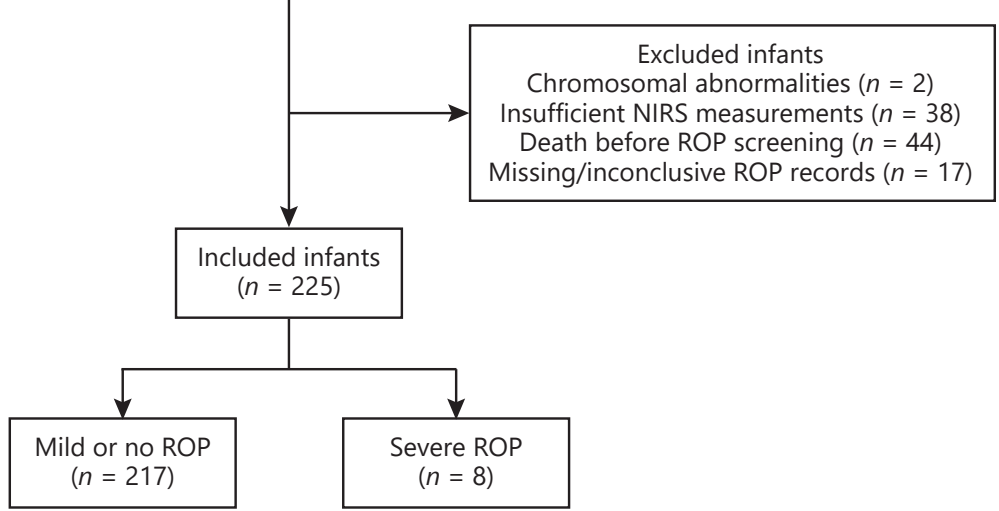

peroxia, leading to downregulation of angiogenesis $[2,3]$. With retinal maturation, an increasingly hypoxic environment causes formation of new but fragile vessels, vitreous and retinal hemorrhage, and retinal detachment [4].

Previous trials evaluating the effects of high (91-95\%) versus low (85-89\%) $\mathrm{SaO}_{2}$ targets in preterm infants demonstrated a reduced risk of ROP at the lower target range, while the opposite was true for mortality and the risk of necrotizing enterocolitis [5]. These findings may have led toward an increased acceptance of rather high $\mathrm{SaO}_{2}$ levels. Therefore, efforts to reduce ROP need to focus on hyperoxia at the tissue level instead, which may be a better target for intervention [6].

Unfortunately, noninvasive retinal oximetry is unavailable for standard neonatal care [7]. Instead, the regional cerebral tissue oxygen saturation $\left(\mathrm{r}_{\mathrm{c}} \mathrm{SO}_{2}\right)$ measured with near-infrared spectroscopy (NIRS) could provide a good estimate of the retinal oxygen saturation considering the close anatomic and developmental relationship between retina and brain $[4,8,9]$. The primary aim of this study was therefore to determine the association between the development of severe ROP and a burden of cerebral hyperoxia within the first days after birth. Secondarily, this study addresses the association between severe ROP and a burden of arterial hyperoxia.

\section{Methods}

Study Design and Participants

Infants born at 30 weeks' gestation or less and admitted to our neonatal intensive care unit (NICU) between January 2012 and
2017 were eligible for retrospective inclusion. Exclusion criteria were chromosomal abnormalities, lack of sufficient cerebral NIRS data, death before ROP screening, and missing screening records. The local Institutional Ethics Committee approved this study.

\section{Cerebral NIRS and Pulse Oximetry}

At our NICU, $\mathrm{r}_{\mathrm{c}} \mathrm{SO}_{2}$ is routinely and continuously measured in infants with a gestational age (GA) below 32 weeks during the first week after birth using the INVOS 5100C near-infrared spectrometer (Medtronic, Dublin, Ireland). The corresponding neonatal sensor was placed on either frontoparietal side of the head. $\mathrm{SaO}_{2}$ was continuously measured using Nellcor pulse oximetry (Medtronic, Dublin, Ireland). The clinical $\mathrm{SaO}_{2}$ target range was initially set at $85-92 \%$ (with alarm limits of $80-92 \%$ ), but changed in December 2014 to $90-92 \%$ (alarm limits 86-93\%). Both $\mathrm{r}_{\mathrm{c}} \mathrm{SO}_{2}$ and $\mathrm{SaO}_{2}$ were recorded at 5-s intervals. Artifacts were manually removed in cases of documented sensor misplacement and sensor misplacement suggested by large nonphysiologic changes $(>20 \%$ saturation difference between 2 consecutive data points) or prolonged missing physiologic variance (same saturation value over at least 20 min, excluding an $\mathrm{r}_{\mathrm{c}} \mathrm{SO}_{2}$ of $95 \%$ as the used device is truncated at this value). Interpolation was not performed. A minimum of $12 \mathrm{~h}$ of measurements within the first $96 \mathrm{~h}$ after birth was considered sufficient for inclusion.

\section{Burden of Hyperoxia}

We calculated the burden of cerebral and arterial hyperoxia as the percentage of measured time spent above saturation thresholds of 85 and $90 \%$, respectively, during the first 4 days after birth. The $\mathrm{r}_{\mathrm{c}} \mathrm{SO}_{2}$ threshold of $85 \%$ represents the 90th percentile of normal reference values in neonates below 30 weeks GA within $72 \mathrm{~h}$ after birth [10]. Values above this level have been associated with neurodevelopmental delay, which may involve mechanisms similar to those involved in ROP [11-13]. The $\mathrm{SaO}_{2}$ threshold of $90 \%$ was chosen based on outcomes associated with saturation targets used by previously mentioned trials. However, to evaluate our choice of 
thresholds, we additionally calculated the cerebral and arterial hyperoxic burden for thresholds of 80 and $90 \%\left(\mathrm{r}_{\mathrm{c}} \mathrm{SO}_{2}\right)$ and 92 and $95 \%\left(\mathrm{SaO}_{2}\right)$.

\section{ROP Data}

ROP was diagnosed by dilated eye exam according to the revised International Classification [14]. Screening was first performed 5-7 weeks after birth depending on GA and repeated every 2 weeks until complete retinal vascularization, but at least once a week in case of disease. Outcomes were collected from patient files. The most severe form of ROP was recorded. Severe ROP was defined as prethreshold disease type 1 according to the ETROP criteria for treatment-requiring ROP [15].

\section{Statistics}

Illustrations were designed using GraphPad Prism version 8.0 for Windows (GraphPad software, La Jolla, CA, USA). Analyses were performed using the software SPSS 24.0 (IBM Corporation, Armonk, NY, USA). We used logistic regression analyses to assess the association between severe ROP and the burden of cerebral and arterial hyperoxia using a $p$ value of 0.05 . If clinical variables with potential influence on both ROP development and $\mathrm{r}_{\mathrm{c}} \mathrm{SO}_{2} / \mathrm{SaO}_{2}$ within the first $96 \mathrm{~h}$ after birth, such as GA, birth weight z-score/ being small-for-GA, head circumference z-score, ventilation, antenatal magnesium sulfate, histologic chorioamnionitis, sepsis, the need for red blood cell transfusions, a hemodynamically significant patent ductus arteriosus, or intraventricular hemorrhage, confounded the relationship between the burden of cerebral or arterial hyperoxia and ROP by affecting the OR to develop severe ROP by $\geq 10 \%$, we entered them in our multivariate regression models.

\section{Results}

\section{Population Characteristics}

Within the study period, 326 infants with a GA of $\leq 30$ weeks were admitted to our NICU. Of these, 225 patients were included for analysis. Figure 1 depicts a detailed inclusion flowchart. Median GA was 28.0 weeks (interquartile range [IQR] 26.7-29.0 weeks) and mean birth weight $1,032 \mathrm{~g}$ (281 g SD). Thirty infants developed mild and 8 infants severe ROP. Seven infants were treated with laser therapy. Clinical differences between infants with and without severe ROP are shown in Table 1.

\section{Burden of Cerebral Hyperoxia and ROP}

Data rejection due to sensor displacement was $<1 \%$ for both infants with and without severe ROP. The median duration of NIRS measurements was 72.2 h (IQR 55.781.0) for infants with severe ROP and $72.2 \mathrm{~h}$ (IQR 55.081.4) for those without. Median $\mathrm{r}_{\mathrm{c}} \mathrm{SO}_{2}$ was $80 \%$ (IQR 68$89 \%$ ) and $77 \%$ (IQR 73-82\%), respectively. Infants with severe ROP had a higher burden of cerebral hyperoxia than infants without severe ROP (median time spent above $85 \% \quad \mathrm{r}_{\mathrm{c}} \mathrm{SO}_{2}: 30 \%$ (IQR $3-76 \%$ ) vs. $16 \%$ (IQR

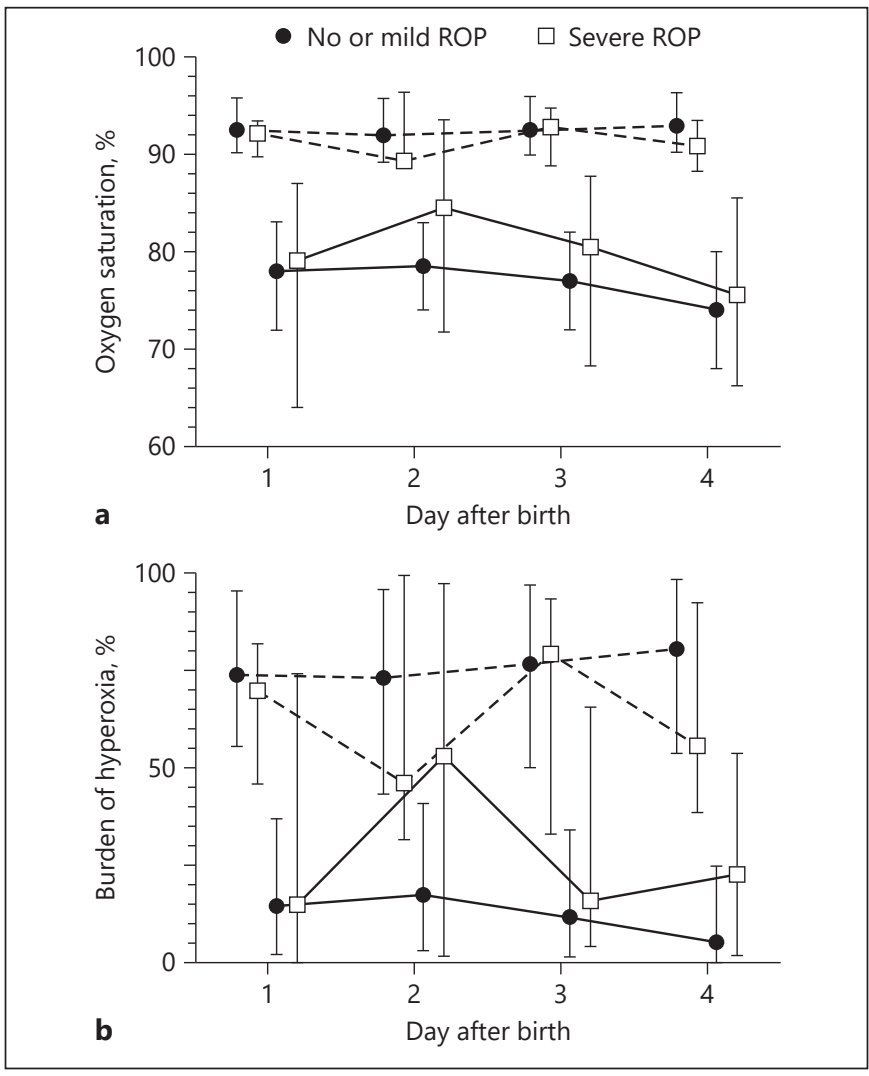

Fig. 2. The course of arterial and cerebral oxygenation during the first 4 days (i.e., the first $96 \mathrm{~h}$ ) after birth in infants with and without severe ROP. a Depicts the average daily arterial (dashed lines) and cerebral (solid lines) oxygen saturation $\left(\mathrm{SaO}_{2}\right.$ and $\mathrm{r}_{\mathrm{c}} \mathrm{SO}_{2}$, respectively) for infants with and without severe ROP. b Depicts the daily arterial (dashed lines) and cerebral (solid lines) burden of hyperoxia, defined as the percentage of time spent above $90 \% \mathrm{~S}_{\mathrm{a}} \mathrm{O}_{2}$ and $85 \% \mathrm{r}_{\mathrm{c}} \mathrm{SO}_{2}$, respectively, for infants with and without severe ROP. Squares and dots represent medians, error bars represent the IQR. ROP, retinopathy of prematurity.

5-33\%)). Figure $2 \mathrm{a}$ and $\mathrm{b}$ depict the daily cerebral oxygenation patterns. In both groups, the median time spent at cerebral hyperoxic ranges was largest on day $2(53 \%$ in those with severe ROP and $17 \%$ in those without). Adjusted for GA, the burden of cerebral hyperoxia within the first $96 \mathrm{~h}$ after birth was significantly associated with the development of ROP (Table 2). For every 10\% more time spent above $\mathrm{ar}_{\mathrm{c}} \mathrm{SO}_{2}$ threshold of $85 \%$ during the first 4 days after birth, the risk for developing severe ROP increased with an OR of 1.50 (95\% CI 1.09-2.06, $p=0.013$ ).

To explore how the choice of our $\mathrm{r}_{\mathrm{c}} \mathrm{SO}_{2}$ threshold influenced our results, subanalyses with different thresholds were performed. Raising the threshold to $90 \%$ strengthened the associations between ROP and the burden of cerebral hyperoxia (adjusted OR per 10\% burden increase: 
Table 1. Clinical population characteristics

\begin{tabular}{|c|c|c|c|}
\hline & $\begin{array}{l}\text { Severe ROP } \\
(n=8)\end{array}$ & $\begin{array}{l}\text { No or mild ROP } \\
(n=217)\end{array}$ & $p$ value \\
\hline \multicolumn{4}{|l|}{ Maternal and gestational characteristics } \\
\hline Multiple gestation & $2(25)$ & $53(24)$ & 0.970 \\
\hline Maternal PE \pm HELLP syndrome & $1(13)$ & $31(14)$ & 0.887 \\
\hline Antenatal $\mathrm{MgSO}_{4}$ & $5(63)$ & $157(75)$ & 0.421 \\
\hline Histologic chorioamnionitis & $1(14)$ & $85(44)$ & 0.116 \\
\hline Delivery by caesarian section & $6(75)$ & $107(49)$ & 0.154 \\
\hline \multicolumn{4}{|l|}{ Neonatal characteristics } \\
\hline Gender, male & $4(50)$ & $101(47)$ & 0.847 \\
\hline Gestational age, weeks & $26.5[25.3$ to 28.1$]$ & $28.0[26.7$ to 29.0$]$ & $0.083^{* *}$ \\
\hline Birth weight, g & $745[620$ to 773$]$ & $1,000[800$ to 1,300$]$ & $0.002 *$ \\
\hline Birth weight ( $z$-score) & $-1.49[-5.02$ to -0.47$]$ & $-0.89[-1.93$ to -0.15$]$ & 0.155 \\
\hline Small-for-gestational age & $3(38)$ & $52(24)$ & 0.382 \\
\hline Head circumference, $\mathrm{cm}$ & $23[22$ to 24$]$ & $26[24$ to 27$]$ & $0.002^{*}$ \\
\hline Head circumference ( $z$-score) & $-1.29[-3.12$ to -0.06$]$ & $-0.70[-1.36$ to -0.07$]$ & 0.282 \\
\hline Apgar score at $5 \mathrm{~min}$ & $7[6$ to 8$]$ & $7[6$ to 8$]$ & 0.883 \\
\hline Mechanical ventilation & $8(100)$ & $163(75)$ & 0.106 \\
\hline Duration of mechanical ventilation, days & $18[7$ to 26$]$ & $2[1$ to 10$]$ & $0.006^{*}$ \\
\hline hsPDA & $3(38)$ & $90(42)$ & 0.823 \\
\hline Necrotizing enterocolitis & $3(38)$ & $31(14)$ & $0.072^{* *}$ \\
\hline Sepsis & $1(13)$ & $72(33)$ & 0.220 \\
\hline $\mathrm{RBC}$ transfusions & $7(88)$ & $142(66)$ & 0.200 \\
\hline \multicolumn{4}{|l|}{ Intraventricular hemorrhage } \\
\hline Grade I/II & $2(25)$ & $55(25)$ & 0.982 \\
\hline Grade III/IV & $0(0)$ & $9(4)$ & 0.557 \\
\hline $\mathrm{BPD}$ & $6(75)$ & $81(37)$ & $0.032 *$ \\
\hline Dexamethasone treatment & $4(50)$ & $31(14)$ & $0.006^{*}$ \\
\hline Death before discharge & $0(0)$ & $6(3)$ & 0.634 \\
\hline \multicolumn{4}{|c|}{$\begin{array}{l}\text { Data are presented as medians [interquartile range] or absolute numbers (percentages). BPD, bronchopul- } \\
\text { monary dysplasia (defined as the need for oxygen } \geq 21 \% \text { for } \geq 28 \text { days at } 36 \text { weeks postmenstrual age or discharge); } \\
\text { HELLP, Hemolysis, Elevated Liver enzymes }(>70 \mathrm{iU} / \mathrm{L}) \text { and Low Platelets }\left(<100 \times 10^{6}\right) \text {; hsPDA, hemodynami- } \\
\text { cally significant (i.e., treatment-requiring) patent ductus arteriosus; } \mathrm{MgSO}_{4} \text {, magnesium sulfate; RBC, red blood } \\
\text { cell; ROP, retinopathy of prematurity; PE, preeclampsia (defined as pregnancy induced hypertension with pro- } \\
\text { teinuria [protein to creatinine ratio } \geq 0.3 \mathrm{~g} / 10 \mathrm{mmol} \text { or } 0.3 \mathrm{~g} \text { in } 24 \text {-h urine]). }{ }^{\star} \text { and }{ }^{\star *} \text { Difference between infants } \\
\text { with and without severe ROP at the } 5 \text { and } 10 \% \text { significance level, respectively, as tested with Mann-Whitney U } \\
\text { or } t \text { test. }\end{array}$} \\
\hline
\end{tabular}

$1.81 ; 95 \%$ CI 1.23-2.67, $p=0.003)$. Lowering the threshold to $80 \%$ eliminated all statistical significance (Table 2).

\section{Burden of Arterial Hyperoxia and ROP}

$\mathrm{SaO}_{2}$ was continuously measured for a median duration of 92 (IQR 92-94) and 94 (IQR 91-95) hours in infants with and without severe ROP, respectively. Median daily $\mathrm{SaO}_{2}$ values were similar between infants with and without severe ROP (Fig. 2a) with a total average of $91 \%$ (IQR 90-93\%) versus 92\% (IQR 90-95\%), respectively. The median total burden of arterial hyperoxia was, however, lower in infants with severe ROP (57\%, IQR 48-78\%) than in infants without (72\%, IQR 52-94\%, Fig. 2b) and not associated with the development of severe ROP (Table 2). Raising the arterial hyperoxic threshold to $95 \%$ did not change this.

\section{Discussion}

High $\mathrm{SaO}_{2}$ levels have been associated with the development of ROP, but cannot always be avoided in practice. Our study aimed to assess whether postnatal cerebral hyperoxia - functioning as a surrogate for retinal hyperoxia - is related to severe ROP. Our findings indeed suggest that a burden of cerebral hyperoxia within the first $96 \mathrm{~h}$ 
Table 2. The association between a burden of cerebral and arterial hyperoxia and the development of severe ROP $(n=8$, total $n=225)$ as assessed by logistic regression analyses, unadjusted and adjusted for gestational age

\begin{tabular}{|c|c|c|c|c|c|c|c|c|}
\hline & $\mathrm{B}$ & SE & $\begin{array}{l}\text { OR }(95 \% \mathrm{CI}) \text { per } \\
10 \% \text { burden increase }\end{array}$ & $p$ value & $\mathrm{aB}$ & aSE & $\begin{array}{l}\text { aOR }(95 \% \mathrm{CI}) \text { per } \\
10 \% \text { burden increase }\end{array}$ & $p_{\text {a }}$ value \\
\hline \multicolumn{9}{|l|}{ Burden of cerebral hyperoxia } \\
\hline $85 \% \mathrm{r}_{\mathrm{c}} \mathrm{SO}_{2}$ threshold & 0.307 & 0.147 & $1.36(1.02-1.81)$ & $0.036^{*}$ & 0.404 & 0.162 & $1.50(1.09-2.06)$ & $0.013 *$ \\
\hline $90 \% \mathrm{r}_{\mathrm{c}} \mathrm{SO}_{2}$ threshold & 0.459 & 0.175 & $1.58(1.12-2.23)$ & $0.009^{*}$ & 0.594 & 0.197 & $1.81(1.23-2.67)$ & $0.003^{*}$ \\
\hline $92 \% \mathrm{SaO}_{2}$ threshold & -0.118 & 0.144 & $0.89(0.67-1.18)$ & 0.412 & -0.008 & 0.159 & $0.99(0.72-1.36)$ & 0.960 \\
\hline $95 \% \mathrm{SaO}_{2}$ threshold & -0.118 & 0.152 & $0.89(0.66-1.20)$ & 0.438 & -0.012 & 0.164 & $0.98(0.72-1.36)$ & 0.940 \\
\hline
\end{tabular}

Primary analyzed thresholds are bolded. aOR, adjusted odds ratio; aB, adjusted regression coefficient; aSE, adjusted standard error; $\mathrm{B}$, regression coefficient; $\mathrm{OR}$, odds ratio; $p_{\mathrm{a}}$, adjusted $p$ value; $\mathrm{r}_{\mathrm{c}} \mathrm{SO}_{2}$, regional cerebral tissue oxygen saturation; ROP, retinopathy of prematurity; $\mathrm{SaO}_{2}$, arterial oxygen saturation; $\mathrm{SE}$, standard error. * Association between a hyperoxic burden and severe $\mathrm{ROP}$ at the $5 \%$ significance level.

after birth increases the risk of severe ROP. Interestingly, we were unable to demonstrate such an association between severe ROP and arterial hyperoxia.

Another study primarily analyzed the association between cerebral hyperoxia and ROP and also reported an association between a cerebral hyperoxic burden within the first $96 \mathrm{~h}$ after birth and treatment-requiring ROP [16]. In this study, the cerebral fractional tissue oxygen extraction (FTOE) instead of $\mathrm{r}_{\mathrm{c}} \mathrm{SO}_{2}$ was used to calculate the burden of cerebral hyperoxia. Cerebral FTOE is calculated as the fraction of arterial oxygen supply that is extracted by the tissue. Reflecting the balance between oxygen supply and consumption, it is commonly used as an indicator of ischemia [17]. Cerebral $\mathrm{rSO}_{2}$, however, provides information about the absolute value of excess oxygen leaving the regional tissue, as it mainly reflects the venous oxygen content in brain tissue after extraction [17]. Irrespective of the relative amount of extracted oxygen, it may be a more sensitive parameter to assess cerebral hyperoxia and less prone to error than FTOE.

Within the SafeBoosC trial, the influence of a burden of cerebral hyperoxia during the first $72 \mathrm{~h}$ after birth on the development of severe ROP was assessed as well [18]. They did not find a difference in risk between infants at the upper quartile of burden $(\geq 14.2 \% \mathrm{~h})$ and infants with a lower burden of hyperoxia. However, only 2 infants with ROP were included in the upper quartile. Our data, not being reduced and categorized into quartiles, suggest that for every $10 \%$ more time an infant spends at cerebral hyperoxic ranges doubles the risk of severe ROP.
The choice of our cerebral hyperoxic threshold of $85 \%$ deviates from threshold values proposed by other studies. The SafeBoosC trial for instance uses a threshold of $85 \%$ as measured with an adult sensor, which represents 2 SDs above the mean in infants below a GA of 32 weeks [19]. As the neonatal sensor used at our institution measures $10 \%$ higher than the adult sensor [10], in our slightly younger study population this would translate to a threshold of 90-95\%. Indeed, a burden exceeding a threshold of $90 \%$ had an even stronger association with ROP. Our primary findings suggest, however, that the risk of ROP already increases at cerebral saturations exceeding a threshold as low as $85 \%$ when using a neonatal sensor. Nonetheless, when interpreting our data, different sensors or devices may implicate different $\mathrm{r}_{\mathrm{c}} \mathrm{SO}_{2}$ thresholds [20].

We did not find an association between a burden of arterial hyperoxia and severe ROP, which supports the findings of Vesoulis et al. [16]. This is seemingly in contrast to the results of the SUPPORT and BOOST trials, which found that $\mathrm{SaO}_{2}$ targets above $90 \%$ increase the risk for severe ROP compared to targets below $90 \%[21,22]$. Although the COT trial was unable to find a difference in risk between $\mathrm{SaO}_{2}$ targets below or above 90\% [23], metaanalysis of the shared database of all 3 trials revealed a significantly increased risk of ROP in infants with higher $\mathrm{SaO}_{2}$ targets [24]. Of note, at birth the infants of these trials were slightly younger and smaller than our study population, making them more susceptible to hyperoxia. Furthermore, the actually measured median $\mathrm{SaO}_{2}$ values were higher than target saturations defined in advance (89\% in the BOOST, $92 \%$ in the COT, and $93 \%$ in the 
SUPPORT trial) with substantial overlap between both target groups, while the initial $\mathrm{SaO}_{2}$ target range at our institution was set between 85 and 92\% (later 90-92\%), which overlaps with both target ranges of the oxygen trials and avoids extremely low and high $\mathrm{SaO}_{2}$ values. This strict oxygen policy, adopting narrow target ranges as recommended after abovementioned oxygen trials, may explain the lack of association with ROP for any of the examined thresholds.

Another explanation for a lack of association between ROP and arterial hyperoxia may be found in the study duration. Although the immediate postnatal period is likely to play a significant role in the pathophysiology of ROP due to an abrupt change in oxygenation after preterm birth, hyperoxia may play a role up to 32-34 weeks GA [25]. However, during the first days after birth, cerebral and not arterial hyperoxia was associated with severe ROP. Moreover, while infants with severe ROP were observed to spent more time at cerebral hyperoxic levels, the time spent at arterial hyperoxic levels was actually less (although statistically insignificant). This discrepancy between cerebral and arterial oxygenation can possibly but not exclusively also be attributed to a greater cerebral immaturity with lower cerebral metabolism and hence lower oxygen consumption and extraction in infants with severe ROP, who were younger and smaller than those without severe ROP $[10,26]$. In turn, this may cause an earlier and stronger relationship between severe ROP and the venous cerebral oxygen saturation rather than the arterial oxygen saturation and may explain why reduction of the cerebral hyperoxic burden proves difficult despite strict oxygen management $[27,28]$.

We recognize some limitations of our study. First, the retrospective nature of data collection may have introduced bias, although limited since a lack of NIRS data was only given by a potential shortage of equipment and not dictated by patient characteristics. Second, our sample size - particularly with regard to the small number of infants developing severe ROP - may have caused us to overinterpret or miss significant associations. Third, due to the nature of our study, which required survival of infants for at least 5 weeks after birth in order to participate, we were not able to investigate mortality in relation to $\mathrm{r}_{\mathrm{c}} \mathrm{SO}_{2}$. Our descriptive patient characteristics, however, suggest that there may be a trade-off between ROP and intraventricular hemorrhage, the latter of which has been related to cerebral hypoxia. Final, we were not able to report the fraction of inspired oxygen $\left(\mathrm{FiO}_{2}\right) \cdot \mathrm{FiO}_{2}$ may be an important parameter as it influences $\mathrm{SaO}_{2}$ and thereby $\mathrm{r}_{\mathrm{c}} \mathrm{SO}_{2}$. However, since we report $\mathrm{SaO}_{2}$, we regard $\mathrm{FiO}_{2}$ less important to report.

Cerebral Hyperoxia and ROP
In summary, our data support a strong relationship between ROP and prolonged periods of cerebral hyperoxia within the first days after birth. Moreover, $\mathrm{r}_{\mathrm{c}} \mathrm{SO}_{2}$ may be more sensitive to early detect infants at risk for severe ROP than $\mathrm{SaO}_{2}$. Further trials are recommended to determine the association between cerebral hyperoxic burden and cerebral metabolism, the practicality of reducing cerebral hyperoxia within the first days after birth, and its effect on the development of severe ROP, neurological outcome, and mortality.

\section{Acknowledgments}

We thank Kai van Amsterdam and Fred de Geus for their technical support and Prof. Dr. H. M. Boezen for her statistical expertise and advice.

\section{Statement of Ethics}

Written informed consent of study participants (or their parents or guardians) was not obtained, as all data were collected as part of routine clinical care and have been anonymized for the purpose of analysis and presentation. Publication of the results was approved by the institutional ethics committee on human research.

\section{Disclosure Statement}

The authors have no conflicts of interest to declare.

\section{Funding Sources}

This research project was part of the research program of the Research Institute of Behavioral and Cognitive Neurosciences, Graduate School of Medical Sciences, University of Groningen, participation in which is financially supported by the Junior Scientific Master Class of the University of Groningen.

\section{Author Contributions}

A.E.R.: contributed to the study design, collected, analyzed and interpreted the data, and drafted the initial manuscript. E.A.H.: contributed to the study design, acquisition and interpretation of data, and critically reviewed the manuscript for intellectual content. E.M.W.K. and A.F.B.: conceptualized and designed the study, supervised data collection and interpretation, and critically reviewed and revised the manuscript for intellectual content; all authors approved the final manuscript as submitted and agree to be accountable for all aspects of the work. 


\section{References}

1 Zin A, Gole GA. Retinopathy of prematurityincidence today. Clin Perinatol. 2013 Jun; 40(2):185-200.

2 Cayabyab R, Ramanathan R. Retinopathy of Prematurity: Therapeutic Strategies Based on Pathophysiology. Neonatology. 2016;109(4): 369-76.

3 Moreton RB, Fleck BW, Fielder AR, Williams CA, Butler L, Wilson C, et al.; BOOST-II UK Collaborative Group. The effect of oxygen saturation targeting on retinal blood vessel growth using retinal image data from the BOOST-II UK Trial. Eye (Lond). 2016 Apr; 30(4):577-81

4 Hellström A, Smith LE, Dammann O. Retinopathy of prematurity. Lancet. 2013 Oct; 382(9902):1445-57.

5 Askie LM, Darlow BA, Davis PG, Finer N, Stenson B, Vento M, et al. Effects of targeting lower versus higher arterial oxygen saturations on death or disability in preterm infants. Cochrane Database Syst Rev. 2017 Apr; 4:CD011190.

6 Pellicer A, Greisen G, Benders M, Claris O, Dempsey E, Fumagalli M, et al. The SafeBoosC phase II randomised clinical trial: a treatment guideline for targeted near-infrared-derived cerebral tissue oxygenation versus standard treatment in extremely preterm infants. Neonatology. 2013;104(3):171-8.

7 Vehmeijer WB, Magnusdottir V, Eliasdottir TS, Hardarson SH, Schalij-Delfos NE, Stefánsson E. Retinal Oximetry with Scanning Laser Ophthalmoscope in Infants. PLoS One. 2016 Feb;11(2):e0148077.

8 London A, Benhar I, Schwartz M. The retina as a window to the brain-from eye research to CNS disorders. Nat Rev Neurol. 2013 Jan; 9(1):44-53.

9 Cabrera DeBuc D, Somfai GM, Koller A. Retinal microvascular network alterations: potential biomarkers of cerebrovascular and neural diseases. Am J Physiol Heart Circ Physiol. 2017 Feb;312(2):H201-12.

10 Alderliesten T, Dix L, Baerts W, Caicedo A, van Huffel S, Naulaers G, et al. Reference values of regional cerebral oxygen saturation during the first 3 days of life in preterm neonates. Pediatr Res. 2016 Jan;79(1-1):55-64.
11 Yiş U, Kurul SH, Kumral A, Cilaker S, Tuğyan $\mathrm{K}$, Genç S, et al. Hyperoxic exposure leads to cell death in the developing brain. Brain Dev. 2008 Oct;30(9):556-62.

12 Benderro GF, Sun X, Kuang Y, Lamanna JC. Decreased VEGF expression and microvascular density, but increased HIF- 1 and $2 \alpha$ accumulation and EPO expression in chronic moderate hyperoxia in the mouse brain. Brain Res. 2012 Aug;1471:46-55.

13 Verhagen EA, Van Braeckel KN, van der Veere CN, Groen H, Dijk PH, Hulzebos CV, et al. Cerebral oxygenation is associated with neurodevelopmental outcome of preterm children at age 2 to 3 years. Dev Med Child Neurol. 2015 May;57(5):449-55.

14 International Committee for the Classification of Retinopathy of Prematurity. The International Classification of Retinopathy of Prematurity revisited. Arch Ophthalmol. 2005 Jul;123(7):991-9.

15 Early Treatment For Retinopathy Of Prematurity Cooperative Group. Revised indications for the treatment of retinopathy of prematurity: results of the early treatment for retinopathy of prematurity randomized trial. Arch Ophthalmol. 2003 Dec;121(12):168494.

16 Vesoulis ZA, Lust CE, Liao SM, Trivedi SB, Mathur AM. Early hyperoxia burden detected by cerebral near-infrared spectroscopy is superior to pulse oximetry for prediction of severe retinopathy of prematurity. J Perinatol. 2016 Nov;36(11):966-71.

17 van Bel F, Lemmers P, Naulaers G. Monitoring neonatal regional cerebral oxygen saturation in clinical practice: value and pitfalls. Neonatology. 2008;94(4):237-44.

18 Plomgaard AM, Alderliesten T, Austin T, van Bel F, Benders M, Claris O, et al. Early biomarkers of brain injury and cerebral hypoand hyperoxia in the SafeBoosC II trial. PLoS One. 2017 Mar; 12(3):e0173440.

19 Hyttel-Sørensen S, Austin T, van Bel F, Benders M, Claris O, Dempsey EM, et al. Clinical use of cerebral oximetry in extremely preterm infants is feasible. Dan Med J. 2013 Jan; 60(1):A4533.

20 Dix LM, van Bel F, Baerts W, Lemmers PM. Comparing near-infrared spectroscopy devices and their sensors for monitoring regional cerebral oxygen saturation in the neonate. Pediatr Res. 2013 Nov;74(5):557-63.
21 SUPPORT Study Group of the Eunice Kennedy Shriver NICHD Neonatal Research Network. Carlo WA, Finer NN, Walsh MC, Rich W, Gantz MG, Laptook AR, et al. Target ranges of oxygen saturation in extremely preterm infants. N Engl J Med. 2010;362:1959-69.

22 BOOST II United Kingdom Collaborative Group. BOOST II Australia Collaborative Group, BOOST II New Zealand Collaborative Group, Stenson BJ, Tarnow-Mordi WO, Darlow BA, Simes J, Juszczak E, Askie L, et al. Oxygen saturation and outcomes in preterm infants. N Engl J Med. 2013;368:2094-104.

23 Schmidt B, Whyte RK, Asztalos EV, Moddemann D, Poets C, Rabi Y, et al.; Canadian Oxygen Trial (COT) Group. Effects of targeting higher vs lower arterial oxygen saturations on death or disability in extremely preterm infants: a randomized clinical trial. JAMA. 2013 May;309(20):2111-20.

24 Askie LM, Darlow BA, Finer N, Schmidt B, Stenson B, Tarnow-Mordi W, et al.; Neonatal Oxygenation Prospective Meta-analysis (NeOProM) Collaboration. Association Between Oxygen Saturation Targeting and Death or Disability in Extremely Preterm Infants in the Neonatal Oxygenation Prospective Meta-analysis Collaboration. JAMA. 2018 Jun;319(21):2190-201.

25 Smith LE: Pathogenesis of retinopathy of prematurity. Growth Horm IGF Res. 2004 Jun; 14 Suppl A:S140-4.

26 Olischar M, Klebermass K, Kuhle S, Hulek M, Kohlhauser C, Rücklinger E, et al. Reference values for amplitude-integrated electroencephalographic activity in preterm infants younger than 30 weeks' gestational age. Pediatrics. 2004 Jan;113(1 Pt 1):e61-6.

27 Hyttel-Sorensen S, Pellicer A, Alderliesten T, Austin T, van Bel F, Benders M, et al. Cerebral near infrared spectroscopy oximetry in extremely preterm infants: phase II randomised clinical trial. BMJ. 2015 Jan;350 jan05 2:g7635.

28 Riera J, Hyttel-Sorensen S, Bravo MC, Cabañas F, López-Ortego P, Sanchez L, et al. The SafeBoosC phase II clinical trial: an analysis of the interventions related with the oximeter readings. Arch Dis Child Fetal Neonatal Ed. 2016 Jul;101(4):F333-8. 